\title{
INTERVENÇÃO PRECOCE: REFLEXÕES SOBRE O DESENVOLVIMENTO DA CRIANÇA CEGA ATÉ DOIS ANOS DE IDADE
}

\author{
Gérson Carneiro de Farias*
}

\section{RESUMO}

O artigo envolve a reflexão do processo de desenvolvimento infantil da criança cega até dois anos de idade (período sensório-motor): as aquisições motoras tais como o desenvolvimento da preensão, da linguagem, a noção do objeto, o vínculo mãe/criança, bem como a análise do programa de atendimento em intervenção precoce. A reflexão mostra que o desenvolvimento infantil se dá pelo movimento, favorecendo as estruturas do pensamento e da linguagem, assim como a relação com o ambiente e com as pessoas, particularmente com a mãe. A análise do programa mostra que seu sucesso depende do atendimento direto prestado à criança, com regularidade e continuidade do trabalho em casa, e à família com orientações e integração de esforços.

PALAVRAS-CHAVE: Desenvolvimento sensório-motor - Programa de atendimento em intervenção precoce e criança cega.

\section{INTRODUÇÃO}

A educação especial como linha de pesquisa do programa de pósgraduação em educação da Universidade do Estado do Rio de Janeiro (UERJ) adota um enfoque psicossocial: centrado nas pessoas com deficiências. Ou seja, um delineamento que leva em conta as possibilidades do sujeito para aprender, desenvolver-se, adaptar-se, participar da vida em sociedade e exercitar sua cidadania. A pósgraduação desenvolve pesquisas do tipo Follow-up: efeitos de programas para enriquecimento. Nesse sentido, a proposta desta comunicação é analisar o desenvolvimento da criança cega até dois anos de idade para aplicação de um programa de intervenção precoce do tipo Follow-up com crianças cegas.

De acordo com estudos realizados na área de intervenção precoce, que comparam crianças cegas ${ }^{1}$ com crianças videntes (que enxergam), a seqüência do desenvolvimento da criança cega é igual a da criança

*Mestre e professor Faculdade de Educação Física - UFG 
vidente, porém o ritmo é mais lento, no tocante à postura e a deslocamentos. Os reflexos são análogos, resguardando a função óculo manual da criança que enxerga e que, na criança que não vê, a ausência da visão irá interferir na construção do seu esquema corporal futuro: lateralidade, organização e estruturação espaciais, e na orientação e identificação dos objetos e pessoas (WARREN, 1984).

Tais estudos reforçam ainda que a cegueira é fator de restrição ao processo de desenvolvimento como um todo, acarretando na área da locomoção a perda do equilíbrio, dos reflexos de proteção, da coordenação motora e do sentido de justeza dos passos (MILLER, 1979). Freedman e Cannady (1971) assinalam que a restrição ambiental incide mais no processo de orientação e mobilidade ${ }^{2}$ do que a perda da visão, assim como a síndrome da superproteção, afirmam Warren e Kocon (1974).

Outros fatores que interferem no processo de desenvolvimento infantil da criança cega é o pouco contato da mãe com a criança (BURLINGHAM, 1967; FRAIBERG, SMITH e ADELSON,1965) e a ausência de estimulação vestibular ${ }^{3}$ : mudanças de posição da criança ou balançá-la no colo, por exemplo (WARREN, 1984). Ferrel, Shaw e Deitz (1998) acrescentam que o tempo se encarrega de diminuir a diferença que existe entre as aquisições básicas de desenvolvimento da criança cega em relação à criança vidente, permitindo-nos a reflexão de que um programa de atendimento em intervenção precoce poderá minimizar ainda mais essa diferença (FARIAS, 1995).

Com o objetivo de refletir sobre o desenvolvimento da criança cega até dois anos de idade e a atitude do educador a ser tomada frente ao programa de atendimento em intervenção precoce, o presente artigo foi redigido. O período de desenvolvimento intelectual a ser considerado nesta comunicação é o sensório-motor de Piaget (1975), que indica dois processos de aprendizagem que ocorrem na primeira infância: a) aprendizagem iniciada pela criança e b) aprendizagem facilitada pelo adulto (NUNES,1995; VYGOTSKY, 1989). Contudo, fazendo incursões no pensamento de Wallon (1976) e Vygotsky, nesse sentido, analisar-se-á o desenvolvimento motor, o desenvolvimento da preensão, a noção do objeto, o desenvolvimento 
da linguagem e o vínculo mãe-criança.

\section{ANÁLISE SOBRE O PERÍODO SENSÓRIO-MOTOR}

Com base nesses estudos e levando-se em consideração o período sensório-motor, isto é, do nascimento até dois anos de idade, a criança cega deve ser colocada em ambientes ricos em estímulos auditivos e táteis para que sua audição e mão aprendam a funcionar em conjunto, facilitando desse modo seu processo de locomoção: rolar, arrastar, quadrupedar, equilibrar, apoiar e andar. Com a audição e a mão funcionando em conjunto, ou seja, a manipulação dos objetos ajudará na construção da inteligência prática futura e na noção do objeto, bem como na aquisição da fala. Sobre esse assunto, Vygotsky $(1989$, p. 27-9) esclarece que

antes de controlar o próprio comportamento, a criança começa a controlar o ambiente com a ajuda da fala. Isso produz novas relações com o ambiente, além de uma nova organização do próprio comportamento [...], fala e ação faz parte de uma mesma função psicológica complexa, dirigida para a solução do problema em questão [...], as crianças resolvem suas tarefas práticas com a ajuda da fala, assim como dos olhos e das mãos [...], usando como instrumento não somente os objetos à mão, mas procurando e preparando tais estímulos de forma a tornálos úteis para a solução da questão e para o planejamento de ações futuras.

Em um ambiente rico em estímulos e graças ao movimento, a criança vai desenvolvendo atitude inteligente no mundo que a cerca: a manipulação de objetos e o relacionamento com as pessoas vão se estabelecendo de forma segura e autônoma. Em outras palavras, mediante experiências repetidas, a criança aprende a planejar sua atividade, requisita assistência de outra pessoa, controlando-a e tornandoa parte necessária de sua atividade prática, iniciando desse modo seu processo de aprendizagem. É nesse período, denominado sensório-motor, que a criança constrói gradativamente o conhecimento de si própria e do ambiente na e por meio da sua contínua interação com o ambiente 
físico e social, em um extremo processo de adaptação e progressiva conquista deste ambiente (NUNES, 1995).

\section{DESENVOLVIMENTO COGNITIVO}

De acordo com a teoria de Piaget (1975), é neste período que o desenvolvimento infantil, por meio da motricidade social, progredirá de simples reflexos para a representação e internalização do pensamento. Este período subdivide-se em seis estágios.

1- Reflexos (do nascimento até 1 mês). O comportamento infantil é caracterizado inicialmente por respostas reflexas do próprio corpo da criança e por alguns aspectos do ambiente externo. Alguns refinamentos da ação reflexa ocorrem com as descobertas infantis, por exemplo, alguns objetos são sugados, outros não. Segundo Freedman (1964), neste estágio, a criança pode sorrir em resposta à voz dos pais. Mostra controle geral dos movimentos dos braços e pernas. De um modo geral, o desenvolvimento da criança cega é semelhante ao da criança vidente neste estágio (WARREN, 1984). E, devido à imaturidade motora, a criança tem um período muito longo de dependência do adulto. Necessita de carinho, de atenção, de abrigo, de alimentação e higiene, esclarece Vygotsky (1989).

2- Reação Circular Primária (de 1 a 4 meses). A criança vidente começa a repetir ações que produzem efeitos no ambiente, que a satisfazem e que sejam interessantes para ela. Para Piaget (1975), neste estágio, a repetição das ações se dá somente pelo prazer e não são ainda controladas pelos efeitos no ambiente. Essas ações inicialmente são dirigidas mais para seu próprio corpo do que para os objetos a sua volta. Sendo a cegueira fator de restrição ao processo de desenvolvimento no seu campo de ação no tocante a gesto e rapidez, até o quarto mês a criança cega fará uso da mão e da boca de modo limitado e ao acaso para conhecimento do objeto. O contato corporal, o qual Wallon (1976) chama de diálogo tônico com a mãe e o brinquedo cantado (música), são processos interativos entre mãe e criança que irão fortalecer o desenvolvimento da linguagem futura, reforçando ainda o vínculo afetivo entre os dois. Desse modo, a integração das atitudes do outro na criança se faz mediante seu jogo tônico e, pela experiência vivida de seu corpo em movimento, a criança vem a estruturar as situações afetivas em 
esquemas tônico-emocionais específicos. A criança interioriza um aspecto de outra pessoa e se transforma em função desta, tendo assim seu processo de aprendizagem facilitado (WALLON,1976).

3- Reação Circular Secundária (de 4 a 8 meses). A criança vidente produz ações que causam efeitos no ambiente, que a satisfazem e são interessantes para ela. Este estágio marca o início da orientação eficaz no ambiente. $\mathrm{Na}$ criança cega pode haver atraso nos reflexos e um desenvolvimento motor mais lento. Inicia-se a exploração dos objetos sonoros em experiências auditivas e táteis: a voz da mãe, os passos e o colo. Por exemplo, a criança continua sorrindo em resposta à voz da mãe, mas pode haver uma aversão à voz de estranhos no oitavo mês (WARREN, 1984). Continua o uso da boca e das mãos. A criança começa a produzir sons silábicos, vocalizando e imitando seus mediadores. Isso mostra que a criança cega necessita da ação do outro e do objeto. Ou seja, a ação da criança sobre o seu corpo e sobre os objetos que a rodeiam é fundamental tanto para o desenvolvimento da motricidade e da percepção, quanto para o desenvolvimento das estruturas cognitivas e de linguagem. Nesse sentido, Vygotsky (1989) ressalta que, desde que nasce, a criança está em constante interação com os adultos, que não só asseguram sua sobrevivência, mas também mediam sua relação com o mundo.

4- Reação Circular Secundária de Coordenação (de 8 a 12 meses). O início da intencionalidade é visto neste estágio, em que a criança vidente coordena suas ações em relação ao ambiente de diferentes modos. Usa de meios específicos para atingir fins específicos, demonstrando a organização do seu desenvolvimento no ambiente. A criança antecipa os efeitos de sua ação e os efeitos das ações de outras pessoas. Todavia, a criança cega precisa ser incentivada ao movimento e à procura do objeto sonoro no ambiente. $\mathrm{O}$ controle da cabeça e do tronco nas posições sentada e de pé será ajudado pelo arrastar, quadrupedar e posteriormente andar, seguindo a mesma seqüência do desenvolvimento da criança que enxerga, conforme frisado, porém um pouco mais tarde. Explorando os objetos com as mãos e os pés, será favorecida a coordenação preensãoaudição. O contato imediato com o objeto reforçará a noção do objeto e a compreensão das primeiras palavras. Por exemplo, a criança cega precisa saber que existe alguma coisa, em cuja direção é preciso se movimentar. A imitação e a imagem especular (do espelho), presente na 
criança que vê, será compensada pela ação do adulto (outro) e pelo contato.

O influxo do meio ambiente e as atividades concretas de estimulação vão contribuir para a aquisição da linguagem e a consciência do seu próprio corpo. Observa-se que o sistema motor favorece as bases do desenvolvimento do pensamento lógico e a percepção influi na representação mental (SALTINI, 1994). Ou seja, é da percepção e ação da criança sobre o ambiente que se forma a representação mental da realidade. Assim, a criança cega só poderá pensar o que significa a palavra "bola", por exemplo, depois que tiver tocado ou brincado com ela. Num segundo momento, estará preparada para falar e futuramente até escrever a palavra "bola" que representa a idéia "bola". Caso ela não tenha oportunidade de usar os sentidos do tato, audição, gustação e olfato, para conhecer a realidade, terá dificuldade para representá-la simbolicamente.

A questão é saber qual dos canais de percepção pode substituir a visão para que a criança identifique objetos e pessoas e adquira a estrutura espacial. É possível afirmar que, quando se bloqueia um canal de entrada existem outros canais que se desenvolvem. No caso da criança cega, esta desenvolve outras formas de comunicação, que servem para lhe dar outras percepções e outras dimensões. À medida que as informações vindas do ambiente, processadas pelo Sistema Nervoso Central, mais particularmente pelo córtex cerebral, mediante percepção tátil, auditiva, cinestésica, olfativa ou gustativa, são imediatamente checadas ou integradas com informações armazenadas, memorizadas em um esquema global, sem características visuais, porém táteis, auditivas e de outro tipo daquele objeto concreto com o mundo exterior, forma-se a "imagem" (esquema mental) de relação entre as coisas, entre as partes desse objeto concreto com o mundo externo (as suas qualidades) e os conceitos.

No exemplo acima, ao manipular a bola, a "imagem" (esquema mental) inclui suas características essenciais: redonda, cheia etc., bem como suas relações sociais desenvolvidas frente àquele objeto, tais como brincar, chutar, pegar etc. Por isso, a criança cega não terá dificuldades para aprender se lhe for propiciado estimulação em tempo e de forma adequada, um ambiente rico em experiências onde ela possa trabalhar seus canais de comunicação, favorecendo desse modo seu desenvolvimento como um todo. Eu diria que somente experiências 
sensório-motoras integradas e significativas ajudarão a criança cega a se conhecer, explorar o mundo, elaborar e organizar o seu próprio conhecimento rumo à competência social.

5- Reação Circular Terciária (de 12 a 18 meses). Neste estágio, a criança que enxerga se envolve em atividades de tentativas e erros. Sua ação torna-se mais flexível e ela pode sistematicamente variá-la para obter objetivos específicos. Parece buscar novidades por querer aprender mais sobre o ambiente. A criança cega inicia suas próprias descobertas no ambiente, onde objetos e pessoas se fazem necessários, e a riqueza dos estímulos auditivos e táteis seja uma constante. Isto é, onde a criança possa em experiências repetidas conhecer os objetos, o ambiente e as pessoas. Que ela possa ainda aumentar seu repertório de palavras, sua autonomia frente à mãe, ao pai, a outras pessoas e objetos. A criança cega, segundo Bruno (1993), necessita de vivência corporal significativa para poder organizar sua ação no espaço. Este autor afirma que

a construção da imagem corporal advém também da oportunidade de relacionar-se com crianças da sua idade, para poder perceber o próprio corpo em relação ao do outro, e construir desta forma a noção do eu e do outro (p.22).

A construção de sua identidade se dá na interação e comunicação com o outro, mediante oportunidades de ação sobre o meio e de vivências sensoriais variadas e significativas. Assim, estará sendo construído também seu processo de linguagem e de pensamento.

6- Internalização do Pensamento (de 18 a 24 meses). Este estágio marca o início do pensamento internalizado na criança vidente. Ela necessita se empenhar, não por muito tempo, em atividades de ensaio e erro, para melhor pensar sobre possíveis efeitos que causam. De acordo com Piaget (1975), este estágio é um marco em que a criança liberta suas próprias percepções e ações. Ela começa a ser capaz de imaginar suas ações e conseqüências. Na criança cega, as experiências de andar, sentar, rodar, levantar e transportar, puxar, empurrar, chutar, saltar, correr, subir e descer escadas, atividades de apoio e sem apoio, que envolvem a sua motricidade, auxiliarão a aumentar sua confiança, habilidade, autonomia e independência. A coordenação dinâmica geral 
dessas atividades irá ao encontro da formação de seu esquema corporal futuro. Nesse sentido, os apelos do meio ambiente e a aprendizagem facilitada pelo adulto implicam em novas atribuições do educador precoce. Além de prover um ambiente rico em estímulos, favorecendo sempre que possível a exploração livre pela criança, caberá ao educador: (1) intensificar certas dimensões relevantes desses estímulos; (2) ensinar à criança um repertório de comportamentos adaptativos; e (3) estabelecer consequiências adequadas para essas respostas do sujeito (NUNES,1995). $\mathrm{O}$ que se exige do educador, portanto, é que ele planeje sua atividade, garanta a segurança de um ambiente propício e use de uma metodologia adaptada à ausência da visão, ou seja, auditiva e tátil. Ilustrando, o desenvolvimento da preensão se dará por experiências de enfiar contas, grupar objetos pequenos, esconder e buscar objetos. Essas práticas de exploração vão ajudar a criança na formação de conceito (noção do objeto), e na ampliação de seu repertório de palavras no diálogo com a mãe, pai e parceiros. O desenvolvimento do esquema corporal futuro se dará por experiências do corpo em sensações cutâneas com o meio, tocando os objetos com a boca, arrastando-se e se expondo ao sol e ao vento etc., mediante percepções tátil e auditiva que vão ajudá-la a organizar seu espaço.

Segundo Vygotsky (1989), o desenvolvimento da criança, num primeiro momento, é mediado pelo outro. Num segundo momento, a criança se apropria do comportamento, da cultura e dos modos de funcionamento psicológico do seu grupo cultural, internalizando-os. Isto é, sem a intervenção de outras pessoas a criança se apropria da aprendizagem. A atividade que antes precisou ser mediada passa a ser independente. Assim, o processo de desenvolvimento da criança está enraizado nas ligações entre a sua história social e individual. Ao internalizar as experiências fornecidas pela cultura, a criança reconstrói individualmente os modos de ação realizados externamente e aprende a organizar os próprios processos mentais.

Em outras palavras, a criança, na interação com sua mãe e familiares, vai transformando esse meio familiar em função do atendimento às suas necessidades básicas, assim, transformando a si mesma. Quando ela modifica o ambiente físico e social por meio do seu próprio comportamento, essa mesma modificação vai influenciar seu comportamento futuro. Ou seja, suas aquisições básicas de motricidade, 
cognição, linguagem e competência social. Desse modo podemos concluir que, para Vygotsky (1989), o desenvolvimento da criança acontece a partir das constantes interações com o meio social em que vive mediante aprendizagem.

\section{PROGRAMA DE ATENDIMENTO EM INTERVENÇÃO PRECOCE}

Os programas de intervenção precoce para crianças com necessidades educacionais especiais têm se mostrado efetivo (NUNES, 1995). Esses programas têm uma preocupação em detectar e diagnosticar o problema da criança de forma transdisciplinar ${ }^{4}$. Os procedimentos do diagnóstico incluem: (a) a anamnese, na qual são avaliados os fatores de risco e os dados que constatam a presença de deficiências, realizada por meio da história familiar e dos antecedentes da própria criança; (b) os exames médicos, mediante os quais se procede a análise de anomalias maiores e menores que auxiliam a identificação precoce de quadros de deficiência; (c) a avaliação psicológica, em que se analisa o desenvolvimento da criança, sobretudo nas áreas de motricidade, linguagem, competência social e cognição; (d) e, para completar, a análise da estimulação do ambiente do qual procede a criança. Além disso, são incluídos, quando necessário, exames complementares, tais como os de laboratório, e os encaminhamentos a neuropediatras, oftalmologistas etc. Desse modo, o objetivo principal desses programas é o de impulsionar o desenvolvimento das habilidades básicas das crianças, quer sejam normais, de risco ou com distúrbios no desenvolvimento, em seus primeiros anos de vida, a fim de prevenir ou minorar os "déficits" instalados, ou que poderão se instalar, possibilitandolhes um processo evolutivo tão equilibrado quanto possível.

Segundo Guralnick e Neville (1979), esses programas também promovem a competência social nas crianças. A competência social é um constructo que se integra aos domínios cognitivo, afetivo, motor e de comunicação, portanto, está relacionada às aquisições básicas da criança. Acrescentam eles que esses programas precisam ser imbuídos de entusiasmo, responsabilidade, persistência, sensibilidade e flexibilidade de quem os aplica (os mediadores). A mediação influencia outras relações da criança com outros mediadores, facilitando desse modo às aquisições 
sensório-motoras, refletindo ainda na autonomia e independência da criança. Reforçando este pensamento, Guralnick (1997) acrescenta que a freqüência e a qualidade dos contatos com diferentes adultos, a variedade de brinquedos e materiais disponíveis, o valor da estimulação em diversos ambientes e a segurança (vacinação, nutrição, amor etc.) oferecida pela família vão contribuir para o desenvolvimento da criança. Ou seja, a competência social torna a criança mais segura de suas ações e menos dependente da mãe, mais sociável e mais firme emocionalmente.

Como frisado, a intervenção precoce tem esse propósito, cuja meta é prevenir ou minimizar problemas de desenvolvimento para criança de risco, decorrentes de fatores biológicos, ambientais ou socioculturais. Seu sucesso depende da integração de esforços, da eficiência de quem atende, da comunidade local e da família, em planejar e coordenar os serviços de forma sistêmica. Em outras palavras, seu sucesso depende da estrutura familiar, isto é, se a família tem moradia, plano de saúde, emprego, boa alimentação, da continuidade do trabalho em casa e da frequiência e regularidade no trabalho de intervenção precoce. Isso mostra, uma vez mais, a evidência e a necessidade de uma intervenção efetiva, iniciando-a nas primeiras idades do desenvolvimento infantil, juntamente com um programa adequado ao ambiente familiar e paralelo a um trabalho sistemático de saúde e nutrição. Mostra também a importância do envolvimento dos pais, para que auxiliem efetivamente no desenvolvimento de sua criança, além da orientação individual a eles encarregada em função das condições particulares da própria criança e da prática de atividades que devem realizar com a criança em casa.

O “caderno de linguagem: caminhando juntos", de Sampaio (2000), presta-se a esse serviço, permitindo acompanhar o desenvolvimento da criança, registrar as atividades e servir de intercâmbio entre diferentes profissionais, tais como neuropediatras, oftalmologistas etc. Como ela afirma: um veículo facilitador do processo de intervenção precoce. Desse modo, o "caderno de linguagem: caminhando juntos" descreve toda a história do processo de intervenção precoce na vida da criança, assim como da identidade de quem a escreve: mãe, pai, tia, avó etc. Ele delega e intermedia a passagem da fala oral para a escrita. Refiro-me às mães e/ou responsáveis que, não sabendo ler ou escrever, pedem a uma pessoa amiga que transcreva a sua fala sobre sua criança para o caderno. Neste sentido, o caderno é um ponto de interação entre o 
individual e o coletivo, aberto ao diálogo transdisciplinar, numa perspectiva de longa duração, na medida em que permite um confronto entre as práticas anteriores e posteriores, tornando-se uma prática de representação: representa o trabalho desenvolvido na intervenção precoce, por meio do discurso que a mãe descreve, cuja fonte é a criança. Portanto, ela sabe para quem escreve e como escreve (GÓMES, 2002). As palavras que usa não somente revelam o seu pensar, como também projetam o seu fazer. Resumindo, o "caderno de linguagem: caminhando juntos" testemunha e conta a história da intervenção precoce para as gerações futuras, cumprindo assim seu papel social.

Realizada a avaliação diagnóstica de forma transdisciplinar, o educador elabora, juntamente com a equipe, da qual os pais devem fazer parte, o plano individual de ensino com os objetivos a serem alcançados nas diferentes áreas do desenvolvimento: motor, de linguagem, competência social e cognição, identificando potencialidades e atrasos no desenvolvimento, ou seja, aquilo que a criança é capaz de fazer independentemente (nível de desenvolvimento real) e aquilo que ela faz com ajuda (nível de desenvolvimento potencial). O espaço de atuação do educador de intervenção precoce se dá no intervalo entre o nível de desenvolvimento potencial e o real, a que Vygotsky (1989) denomina zona de desenvolvimento proximal. Por meio dela, podemos dar conta não só dos processos de maturação já completados, mas também dos processos em vias de desenvolvimento, demonstrando que aquilo que uma criança pode fazer com assistência hoje poderá fazer sozinha amanhã. Assim, na criança cega o seu nível de desenvolvimento real, isto é, o que ela consegue fazer sozinha é restringido pela ausência da visão, havendo a necessidade de se trabalhar mais o seu nível de desenvolvimento potencial pela ação do outro. A organização da aprendizagem pelo outro induz o desenvolvimento mental. Trata-se, pois, de apostar na capacidade da criança, propondo um tipo de trabalho que considere mais suas qualidades do que seus defeitos.

Nesse sentido, a ação pedagógica deve ser norteada visando a promover o desenvolvimento das habilidades sensório-motoras da criança. Portanto, recomenda-se: (I) que o educador utilize o ensino real e potencial, isto é, que inicie pelo nível de desenvolvimento real para promover sucesso (motivação), iniciando o trabalho com atividades já conhecidas pela criança. Isso induz novas atividades, e, após, o nível 
potencial com ajuda, transformando o nível de desenvolvimento potencial em real; (II) que o ensino seja funcional, significa criar situações reais de intervenção, ou seja, é mais adequado ensinar à criança cega o conceito de bola quando ela estiver brincando no "play-ground" do que na sala de intervenção; (III) que a estimulação seja adequada $e$ consistente, implica tornar a relação criança/adulto sintonizada com o interesse da criança, ambiente propício, duração do estímulo e observação das respostas; (IV) que se adaptem as atividades às condições da deficiência da criança, por exemplo, se o objetivo é favorecer o desenvolvimento da noção de permanência do objeto à criança cega, os estímulos visuais deverão ser substituídos por auditivos e táteis. No caso da bola, o educador deve balançar a bola com guizo perto da criança e permitir que ela a manuseie. Se a bola é retirada de suas mãos, ela demonstrará a aquisição da noção do objeto esticando a mão para pegála; (V) que se avalie e se registre o desempenho da criança. A avaliação contínua do comportamento da criança faz parte do processo de intervenção precoce. O registro de observação do desempenho da criança de forma sistemática, ao longo do processo e em diferentes situações, favorecerá a demonstração dos progressos e o aperfeiçoamento dos procedimentos do ensino.

Assim, a avaliação do plano de ação do programa de atendimento em intervenção precoce que analisa os efeitos dessa intervenção sobre o desenvolvimento infantil, particularmente o período sensório-motor, demonstra que: (1) os efeitos positivos de um ambiente verbalmente estimulado sobre o desenvolvimento cognitivo dependem, essencialmente, dos padrões mais abstratos da linguagem utilizada no meio familiar e da forma de relacionamento do adulto com a criança; (2) as variáveis ambientais modificam o ritmo e a extensão do processo evolutivo infantil, acelerando-o ou retardando-o, mas não em sua totalidade, já que a sua evolução também depende do substrato biológico que a criança traz consigo. Deduz-se que o enriquecimento adequado de um ambiente precariamente estimulador, efetuado desde os primeiros tempos de vida, repercute favoravelmente no desenvolvimento infantil, compensando, assim, em grande parte, os efeitos negativos das variáveis ambientais inadequadas, (3) e, finalmente, que certas condições do meio circundante podem influir no desenvolvimento infantil, permitindo indicar as linhas básicas dos correspondentes programas de intervenção precoce 
(PÉREZ-RAMOS; PÉREZ-RAMOS, 1996). Portanto, é preciso tornar este ambiente materialmente sustentável, psicologicamente integrado e espiritualmente fecundo: caloroso para a criança e para a mãe.

\section{CONCLUSÃO}

Concluindo, o desenvolvimento da criança cega até dois anos de idade se dá pelo movimento. Não é à toa que Piaget chama esse período de sensório-motor.

De acordo com Wallon, a inter-relação existente entre a intervenção precoce e a motricidade infantil, em que a linguagem, o símbolo e o movimento desempenham importantes papéis, além de apresentar a linguagem corporal como importante meio de comunicação tônico-afetiva, favorece a evolução das estruturas motoras de base, bem como das aprendizagens, que dependem da estrutura genética e ambiental (nutrição, cuidado, estimulação e ensino), que são fatores cruciais para o desenvolvimento (RAMEY; RAMEY S., 1998). Esses fatores afetam não só os padrões de interação mãe/criança em termos de melhoria na quantidade e qualidade, como também as áreas específicas do desenvolvimento da criança, tais como: linguagem e competência social. Assim, a qualidade da relação mãe/filho interfere na evolução da criança.

A complementação alimentar produz benefícios não só sobre o crescimento físico, mas também sobre as áreas comportamentais relacionadas. O período sensório-motor, segundo Piaget, é reconhecido como determinante no desenvolvimento posterior, e, portanto, parece coerente afirmar que as intervenções efetuadas durante este período não só demonstram efeitos imediatos, mas também capacitam a criança à aprendizagem futura.

Um ambiente saudável e os recursos que a comunidade pode prover vão contribuir também para o desenvolvimento da motricidade, da linguagem, da competência social e cognição, bem como da estrutura genética da criança.

Para Vygotsky, o conhecimento é construído socialmente no âmbito das relações humanas. Ou seja, é pela aprendizagem nas relações com os outros que a criança vai construindo seu conhecimento que permite $o$ desenvolvimento mental, afetivo e motor. Em outras palavras, a intervenção precoce adequada e consistente, a aprendizagem no meio 
familiar em rotinas diárias e a convivência social é que trarão a reboque o desenvolvimento da criança cega, amenizando as suas dificuldades, geradas pela ausência da visão. Nesse sentido, o programa de atendimento deve ir ao encontro das necessidades da família, ou seja, na colaboração entre profissionais e responsáveis pela criança e no saber ouvir os pais nas suas crenças, atitudes e valores, para orientá-los no processo de educação da criança.

\title{
Agradecimento
}

Este artigo tem o apoio da Fundação Carlos Chagas Filho de Amparo à Pesquisa do Estado do Rio de Janeiro da Secretaria de Estado de Ciência e Tecnologia (FAPERJ), sob a concessão de bolsa E-26/ 151.240/2002, em parceria com o Programa de Pós-Graduação em Educação da Universidade do Estado do Rio de Janeiro (UERJ). O texto foi produzido na disciplina Linguagem e Comunicação do portador de deficiência do Curso de Doutorado em Educação, e é fruto das discussões em sala de aula sobre os temas referenciados pela bibliografia solicitada pela professora da disciplina. A estas instituições, colegas e professora, meus agradecimentos.

Early Intervention: reflexions upon the development of blind children up to two years of age

\begin{abstract}
This article reflects upon the process of child development in blind children aged up to two years old (sensor-motor period): their acquisition of motor skills such as the development of grabbing, language, the notion of object, the mother-child attachment, and an analysis of the assessment program for early intervention. This reflexion shows that child development happens through movement, which facilitates the structuring of thought and language, as well as the child's relationship with the environment and other people, especially their mothers. An analysis of the program shows that its success depends on the assessment given directly to the child, with frequent and continuous work done at home, as well as the assessment given to the family, throught orientation and joint efforts.

KEY-WORDS: sensor-motor development - assessment program for early intervention - blind children.
\end{abstract}

Intervencion precoz: reflexiones sobre el dearrollo del nino ciego hasta los dos anos de edad 


\section{RESUMEN}

El artículogo envuelve la reflexión del proceso de desarrollo infantil del niño ciego hasta los dos años de edad (período sensorio-motor): las adquisiciones motoras tales como el desarrollo de la aprehensión, del lenguaje, la noción del objeto, el vínculo madre/niño, así como el análisis del programa de atendimiento en intervención precoz. La reflexión muestra que el desarrollo infantil se da por el movimiento, favoreciendo las estructuras del pensamiento y del lenguaje, así como la relación con el ambiente y con las personas, particularmente con la madre. El análisis del programa muestra que su éxito depende del atendimiento directo prestado al niño, co regularidad y continuidad del trabajo en casa, y a la familia con orientaciones e integración de esfuerzos.

PALABRAS CLAVES: desarrollo sensorio-motor - programa de atendimento en intervención precoz y - niñ ciego.

\section{NOTAS}

${ }^{1}$ Do ponto de vista pedagógico, qualquer criança que esteja incapacitada de ver até certos limites pré-fixados, necessitando do Sistema Braille para ler e escrever e outros recursos metodológicos e equipamentos especiais a sua educação (Farias, 1995, p.1).

2 Processo que proporciona à pessoa cega condição de se situar no meio físico em que vive, se movimentar livremente, explorar os objetos que a cercam e adquirir a independência social, isto é, ir e vir na sua comunidade (Farias, 1995, p.19).

${ }^{3}$ A Integração sensorial é pré-requisito para a aprendizagem e desenvolvimento, a exemplo da visão e audição que se completam para ajudar no equilíbrio. $\mathrm{O}$ aparelho vestibular é o órgão responsável pelas sensações de equilíbrio, mesmo que detecte a orientação e os movimentos apenas da cabeça. Este aparelho, aliado às outras fontes de informação, como os impulsos proprioceptivos cervicais ou plantares e as informações visuais, determina as reações do indivíduo em face dos deslocamentos do corpo (Guyton, 1977, p. 618). Considerando serem a visão e audição os dois sentidos nobres que mais nos relacionam com a exterioridade (Oliveira, 2002), a ausência de ambos requer que o organismo lance mão do sentido tátil, gustativo, olfativo e cinestésico para ajudar a relação do indivíduo com as pessoas e os objetos a sua volta, isto é, sua relação espacial e temporal no ambiente. Desse modo, há a necessidade de a criança cega ou surda vivenciar experiências que favoreçam os órgãos internos (interoceptores), os órgãos corporais e 
motores, tátil, cinestésico e vestibulares (proprioceptores), para que no conjunto, numa integração sistêmica no cérebro, inclusive com os órgãos prejudicados: visão e audição, mas que tenham a percepção de luz e do som (teleceptores), construa sistemas funcionais, intra e interneurossensoriais, que estão na base da aprendizagem e desenvolvimento das aquisições básicas de motricidade, linguagem, competência social e cognição.

${ }^{4}$ Entende-se por transdisciplinaridade a colaboração entre profissionais, mediante constante troca de informações, em diálogo aberto, rompendo, de alguma forma, as fronteiras do campo de especialização próprias de cada profissão. Verifica-se a necessidade de formação interfásica para os elementos da equipe, para que seja possível esta inter-relação de experiências (Pérez-Ramos e Pérez-Ramos, 1996, p. 12).

\section{REFERÊNCIAS}

BRUNO, M. M. G. O desenvolvimento integral do Portador de Deficiência Visual: da integração precoce à integração escolar. São Paulo: Laramara, 1993.

BURLINGHAM, D. Developmental considerations in the occupations of the blind. Psychoanalystic Study of the Child. 22, 187-198, 1967.

FARIAS, Gérson Carneiro. Efeitos de um programa de estimulação desenvolvido mediante uma linha de base múltipla para uma aluna cega. Monografia de especialização apresentada no departamento de pós-graduação da Universidade Estadual de Goiás, 1995.

FERREL, K. A; SHAW, A. R.; DEITZ, S. T. A national longitudinal study of the early development of children who are visually impaired. Project Prism. Colorado: UNC, 1-8. 1998.

FRAIBERG, S; SMITH, M.; ADELSON, E. An educational program for blind infants. Journal of Special Education. 3, 121-142, 1965.

FREEDMAN, D. G. Smiling in blind infants and the issue of innate vs. 
acquired. Journal of Child Psychology and Psychiatry, 5, 171-184, 1964.

FREEDMAN, D. A.; CANNADY, C. Delayed emergence of prone locomotion. Journal of Nervous and Mental Disease, 153, 108-117, 1971.

GÓMES, A. C. Historia de la cultura escrita: ideas para el debate. Universidade de Alcalá. (Pp. 1- 26), 2002.

GURALNICK, Michael J. The effectiveness of early intervention. Baltimore: Paul H. Brookes. (Pp.3-20), 1997.

GURALNICK, Michael J.; Nevill, Brian. Designing early intervention to promote children's social competence. In: GURALNICK, Michael J. The effectiveness of early intervention. Baltimore: Paul H. Brookes, p.575-603, 1997.

GUYTON, A. C. Tratado de Fisiologia Médica. Rio de Janeiro: Interamericana, 1977.

MILLER, J. Características gerais do deficiente visual. Em: UNIVERSIDADE DO ESTADO DO RIO DE JANEIRO. Proposta Curricular para Deficientes Visuais. Brasília: MEC, 4, 7-29, 1979.

NUNES, Leila R.O.P. Educação precoce para bebês de risco. Em: B. Rangé (org) Psicologia comportamental e cognitiva. Campinas: Psy (Pp.121-132), 1995.

OLIVEIRA, J. V. G. Do essencial invisível: arte e beleza entre os cegos. Rio de Janeiro: Renavan, 2002.

PÉREZ-RAMOS Aidyl. M. Q. e PÉREZ-RAMOS, J. Estimulação precoce: serviços, programas e currículos. Brasília: COORDE, 1996.

PIAGET, Jean. $O$ nascimento da inteligência na criança. 7. ed. Rio de Janeiro: Zahar, 1975. 
RAMEY, Craig T.; RAMEY, Sharon L. Early intervention and early experience. American Psychologist, 53 (109-120), 1998.

SALTINI, C. A segunda gestação. Globo Ciência. Rio de Janeiro: 56, 36-42, 1994.

SAMPAIO, H. P. e FARIAS, G. C. O caderno de linguagem "Caminhando juntos" como veículo facilitador do processo de intervenção precoce. Temas sobre Desenvolvimento. v. 8, n. 48, p. 43-9, 2000.

VYGOTSKY, L. S. A formação social da mente. São Paulo: Martins Fontes, 1989.

WALLON, H. Do ato ao pensamento. Lisboa: Estampa. 1976.

WARREN, David. H. Blindness and early childhood development. New York: American Foundation for the blind, 1984.

WARREN, D. H. e KOCON, J. A. Factors in the sucessful mobility of the blind: a review. American Foudation for the Blind Research Bulletin, 28, 191-218, 1974.

Recebido: novembro de 2003 Aprovado: dezembro de 2003

Endereço para correspondência Gérson C. Farias email:polianajr@uol.com.br

Rua “C”, Quadra 22, Lt. 16, Setor Progresso - Goiânia - GO CEP: 74580740 